УДК 620.193

\title{
ФОСФОРСОДЕРЖАЩИЕ ПРОДУКТЫ ИЗ ОТХОДОВ ПРОИЗВОДСТВА РИСА И ИХ АНТИКОРРОЗИОННЫЕ СВОЙСТВА
}

\author{
(ㄱ) Н.В. Макаренко", У.В. Харченко, А.Б. Слободюк, Л.А. Земнухова \\ Институт химии Дальневосточного отделения РАН, пр. 100-летия \\ Владивостока, 159, Владивосток 690022 (Россия), e-mail: makarenko@ich.dvo.ru
}

Выделены фосфорсодержащие продукты из мучки и шелухи риса, изучен их элементный состав и строение методами ИК- и ЯМР-спектроскопии, рентгенофазового (РФА) и дифференциально-термического анализа (ДТА). Исследовано влияние фосфорорганических веществ, полученных из отходов производства риса, на коррозию малоуглеродистой стали Ст3 в агрессивных средах гравиметрическим и потенциодинамическим методами, а также с использованием сканирующей электронной микроскопии.

Ключевые слова: рисовая мучка, шелуха, производные фитиновой кислоты, ингибиторы коррозии.

Работа была поддержана грантом ДВО РАН № 09-III-В-04-119 «Азот- и фосфорсодержашие соединения из растительного сырья как ингибиторы коррозии металлов в водных средах».

\section{Введение}

Разработка экологически безопасных соединений, обладающих ингибирующим эффектом, является в настоящее время актуальной проблемой в области защиты металлов. В последние два десятилетия ведутся исследования по поиску и получению так называемых зеленых ингибиторов: более дешевых, легко доступных и снижающих риск воздействия на окружающую среду. Источниками таких веществ могут быть нетоксичные и возобновляемые растительные отходы. В литературе описаны экстракты ряда растений, которые проявляют ингибирующие свойства к различным металлам, но механизм их действия практически не изучен [1-3]. Создание ингибиторов на основе природных соединений является важным решением не только в области защиты металлов, но и в проблеме утилизации многотоннажных отходов сельского хозяйства.

Ранее нами было показано, что экстракты, полученные из плодовых оболочек риса (шелухи, лузги), проявляют защитные свойства от коррозии малоуглеродистой стали Ст3 в водно-солевой и кислой средах [4]. Основными органическими компонентами таких экстрактов являются полисахариды, аминокислоты, фосфорорганические и другие вещества, имеющие набор различных функциональных групп. Фосфор в рисовых отходах находится в основном в виде производных фитиновой или инозитгексафосфорной кисло-

Макаренко Наталья Викторовна - научный сотрудник лаборатории химии редких металлов, кандидат химических наук, тел.: (4232)215-275,

e-mail:makarenko@ich.dvo.ru

Харченко Ульяна Валерьевна - научный сотрудник лаборатории защитных покрытий и морской коррозии, кандидат химических наук, тел.: (4232) 313-301, e-mail: kcharchenko@ich.dvo.ru

Слободюк Арсений Борисович - научный сотрудник лаборатории химической радиоспектроскопии, тел.: (4232) 215-328, e-mail: ampy@ich.dvo.ru Земнухова Людмила Алексеевна - заведующая лабораторией, доктор химических наук, профессор, тел.: (4232) 215-275, e-mail: laz@ich.dvo.ru ты (в шелухе до 2\% и до 6-7\% в мучке) [5]. Состав и структура растительных фосфоинозитидов, как показывают литературные данные последних лет, различаются в зависимости от сырья и способа его переработки: соотношение Р : С в таких продуктах может меняться от $6: 6$ до $1: 6$ [6]. Сведений о соотношении Р : С в веществах, выделяемых из рисовых отходов, нами не найдены.

Настоящая работа посвящена изучению состава фосфорсодержащих продуктов из отходов производства риса (шелухи, мучки) и действию их растворов на коррозию стали Ст3.

\footnotetext{
* Автор, с которым следует вести переписку.
} 


\section{Экспериментальная часть}

Объектами исследования были фосфорсодержащие вещества, выделенные из рисовых отходов (мучки (РМ) и шелухи (РШ)), и в качестве образца сравнения - реактив фирмы «Sigma» (гидрат фитината натрия, $\mathrm{C}_{6} \mathrm{H}_{18} \mathrm{O}_{24} \mathrm{P}_{6} \cdot \mathrm{xNa} \cdot \mathrm{yH}_{2} \mathrm{O}$ ), полученный из риса (однако производителем не указана часть растения, из которой получен реактив).

Экстракцию фитиновой кислоты из рисовых отходов осуществляли по разработанной ранее методике, описанной в [5], путем кислотного гидролиза навесок сырья (20-100 г) 1\% раствором соляной кислоты при соотношении Т:Ж, равном 1:5, при непрерывном перемешивании или без него в течение от 20 мин до 3 ч при температуре $20-80^{\circ} \mathrm{C}$. Экстракт отстаивали, отфильтровывали через бумажный фильтр, промывая остаток сырья $1 \%$ раствором соответствующей кислоты, и направляли раствор на ультрафильтрацию, которую проводили через ацетатцеллюлозные мембраны УАМ-500. Из очищенного таким образом экстракта осаждали соли фитиновой кислоты $10 \%$ растворами гидроксидов натрия или аммония при $\mathrm{pH} 7,0-8,0$, которые затем отделяли от раствора фильтрованием, промывали на фильтре водой, высушивали на воздухе до постоянной массы.

Элементный состав образцов изучен методом рентгено-флуоресцентной спектрометрии с полным отражением на спектрометре TXRF 8030C (Германия). Содержание водорода определяли на CHNS-O элементном автоматическом анализаторе EuroVector EA3000 (Италия).

Рентгенограммы веществ снимали на рентгеновском дифрактометре Bruker D8 ADVANCE (Германия).

ИК-спектры поглощения фосфорсодержащих образцов регистрировали в области 400-4000 см${ }^{-1}$ в вазелиновом масле с использованием Фурье-спектрометра Shimadzu FTIR Prestige-21 (Япония) при комнатной температуре.

Дериватограммы записывали на синхронном анализаторе NETZSCH STA 449C Jupiter (Швейцария), а также на DERIVATOGRAPH Q-1500 (Венгрия) скорость нагрева образцов 5 град/мин.

Спектры ЯМР $\left({ }^{13} \mathrm{C},{ }^{31} \mathrm{P}\right)$ исследуемых образцов записывали на многоядерном цифровом спектрометре для твердого тела фирмы Bruker AV-300 (Германия). Химические сдвиги (ХС) сигналов в спектрах ЯМР ${ }^{13} \mathrm{C}$ измеряли относительно эталона $\mathrm{Si}\left(\mathrm{CH}_{3}\right)_{4}$, а для определения ХС резонансных линий в спектрах ЯМР по фосфору в качестве эталонов использовали разбавленные водные растворы $\mathrm{H}_{3} \mathrm{PO}_{4}$.

Исследование ингибирующего действия фосфорсодержащих веществ проводилось гравиметрическим методом. В качестве стандартных ингибиторов были использованы 1,2,4-триазол и 3-амино-1,2,4триазол [7]. Концентрация всех добавок составляла 0,7 г/л, которые затем растворяли в растворе $3 \% \mathrm{NaCl}$ и 0,1 н. $\mathrm{HCl}$. Образцы марки стали Ст 3 размером $20 \times 20 \times 0,3$ мм предварительно отшлифовывали, обезжиривали ацетоном и взвешивали на аналитических весах. Скорость коррозии $\left(К, \Gamma / \mathrm{M}^{2} \cdot \mathrm{q}\right)$ образцов и степень защиты $(\mathrm{Z}, \%)$ рассчитывали по следующим формулам:

$$
K=\frac{m_{1}-m_{2}}{S t},
$$

где $m_{1}$ - масса образца до экспозиции, г; $m_{2}$ - масса образца после экспозиции, г; $S$ - площадь образца, м²; $t$ - время, ч;

$$
Z=\frac{K-K_{\ni}}{K} \cdot 100 \%
$$

где $K$ и $K_{\text {э }}$ - скорость коррозии Ст3, соответственно, в контроле и с добавкой фосфоинозитида, г $/ \mathrm{M}^{2} \cdot$ ч.

Более детальное изучение ингибирующего действия производных инозитгексафосфорной кислоты было проведено методом снятия потенциодинамических кривых. Электрохимические измерения выполняли в стеклянной трехэлектродной ячейке с хлорсеребряным электродом сравнения и платиновым вспомогательным электродом с использованием потенциостата с интеллектуальным управлением IPC-PRO (Москва).

Морфологию поверхности стальных образцов исследовали на сканирующем электронном микроскопе EVO-50 XPV (LEO, Германия).

Микрозондовый анализ проводили на рентгеновском микроанализаторе JXA-8100 (JEOL, Япония) с тремя волновыми спектрометрами, доукомплектованном энергодисперсионным спектрометром INCA250 (Oxford, Англия). 


\section{Обсуждение результатов}

Исследования показали, что образцы, полученные из РШ и РМ, имеют идентичный состав, поэтому дальнейшие эксперименты проведены с веществами, выделенными из рисовой мучки, выход которых больше. Для получения фосфорсодержащих образцов из РМ использовали $10 \% \mathrm{NH}_{4} \mathrm{OH}$ (образец I) или $10 \% \mathrm{NaOH}$ (образец II).

Результаты элементного анализа фосфорсодержащих веществ даны в таблице 1.

Соотношение элементов в реактиве следующие: $\mathrm{P}: \mathrm{C}=5,6: 6$, что соответствует наличию фрагментов $\mathrm{C}_{6} \mathrm{P}_{6}$ в фитиновой кислоте, а соотношение элементов в выделенных фосфорсодержащих продуктах из рисовой мучки иное: $\mathrm{P}: \mathrm{C}=5,3-5,1: 6$, что свидетельствует о присутствии в изучаемых веществах фрагментов $\mathrm{C}_{6} \mathrm{P}_{5}$, входящих в состав пентофосфоинозитида.

По данным рентгенофазового анализа, реактив гидрат фитината натрия и все фосфорсодержащие соединения (из рисовой мучки) являются рентгеноаморфными.

В ИК-спектре реактива (рис. 1а) присутствуют интенсивные полосы поглощения в области 933-1203 и $515 \mathrm{~cm}^{-1}$, которые, согласно [8], относятся к валентным и деформационным колебаниям связей Р-О. Тетраэдрический ион $\mathrm{PO}_{4}{ }^{3-}$ характеризуется четырьмя нормальными колебаниями, из которых только два активны в ИК-спектре: $v_{3} \sim 1017 \mathrm{~cm}^{-1}$ (валентное) и $v_{4} \sim 567 \mathrm{~cm}^{-1}$. Наличие трех интенсивных полос в ИКспектре реактива «Sigma» (рис. 1a) указывает на низкую симметрию катиона $\mathrm{PO}_{4}{ }^{3-}$. О присутствии групп $\mathrm{OH}^{-}$в реактиве гидрате фитината натрия свидетельствуют полосы поглощения в ИК-спектре в области валентных $\left(3375 \mathrm{~cm}^{-1}\right)$ и деформационных $\left(1659 \mathrm{~cm}^{-1}\right)$ колебаний. Анализ ИК-спектров фосфорсодержащих продуктов из РМ (рис. 1б, в) показывает, что оба образца имеют одинаковые спектры, которые характеризуются наличием только двух полос поглощения в области валентных колебаний групп $\mathrm{PO}_{4}\left(993-996 \mathrm{~cm}^{-1}\right.$ и 1121-1128 $\mathrm{cm}^{-1}$ ), а не трех, как в реактиве «Sigma».

Методом ДТА была определена термостабильность реактива «Sigma» и образца, полученного из рисовой мучки. Гидрат фитината натрия устойчив лишь до температуры $\sim 50{ }^{\circ} \mathrm{C}$, а при дальнейшем нагревании до $225{ }^{\circ} \mathrm{C}$ происходит его разложение. Разложение образца из рисовой мучки начинается, как и в реактиве «Sigma», при температуре $>50^{\circ} \mathrm{C}$.

Для более детального исследования строения изучаемых фосфорсодержащих соединений был привлечен метод ЯМР $\left({ }^{13} \mathrm{C}\right.$ и $\left.{ }^{31} \mathrm{P}\right)$.

Спектр ЯMP ${ }^{13} \mathrm{C}$ реактива фирмы «Sigma» (рис. 2б) представляет собой одиночный сигнал с химическим сдвигом 75 м.д., что свидетельствует об эквивалентности всех атомов углерода в молекуле. Наличие нескольких линий в спектре ЯМР раствора реактива «Sigma» (рис. 2в), вероятнее всего, обусловлено присутствием в растворе различных изомеров. В спектре ЯМР ${ }^{13} \mathrm{C}$ образца, полученного из рисовой мучки (рис. 2a), кроме сигнала, наблюдаемого в реактиве, присутствуют линии с ХС, равными 176, 102, 83, 62 и 28 м.д., на долю которых приходится $40 \pm 10 \%$ всей площади спектра. Появление линий вблизи основного сигнала с XC $=83,62$ м.д., вероятно, обусловлено замещением протонов водорода в молекуле ортофосфорной кислоты на ионы натрия, калия, магния, в соответствии с данными таблицы 1 . В общем случае изменение природы одного заместителя может привести к появлению до четырех типов неэквивалентных атомов углерода.

Таблица 1. Элементный состав реактива «Sigma» и фосфорсодержащих образцов, полученных из рисовой мучки

\begin{tabular}{c|c|c|c}
\hline \multirow{2}{*}{ Элемент } & \multicolumn{3}{|c}{ Содержание, \% } \\
\cline { 2 - 4 } & Реактив «Sigma» & Образец I & Образец II \\
\hline $\mathrm{C}$ & 9,28 & 7,27 & 6,65 \\
$\mathrm{H}$ & 2,72 & 4,39 & 3,56 \\
$\mathrm{O}$ & 55,1 & 55,2 & 54,66 \\
$\mathrm{P}$ & 22,63 & 16,71 & 14,78 \\
$\mathrm{~N}$ & - & 4,0 & - \\
$\mathrm{Mg}$ & - & 8,84 & 7,95 \\
$\mathrm{~K}$ & - & 3,46 & 4,31 \\
$\mathrm{Na}$ & 12,72 & - & 3,03 \\
$\mathrm{Ca}$ & - & 1,04 & 1,11 \\
\hline
\end{tabular}


Спектры ЯМР ${ }^{31} \mathrm{P}$ изучаемых образцов (рис. 3а, б) представляют собой синглеты с ХС 1,6 м.д. (образец из PM) и 0,95 м.д. (реактив «Sigma»). Асимметричная форма спектра ЯМР указывает на отклонение симметрии окружения атома фосфора от кубической (проявляется различная кратность связей Р-О). Центральные компоненты спектров для обоих образцов слегка асимметричны.

Полученные данные свидетельствуют о разном ближайшем окружении атома фосфора в реактиве фирмы «Sigma» и образце, выделенном из РМ. Спектр ЯМР ${ }^{31} \mathrm{P}$ вещества из рисовой мучки в водном растворе значительно уширяется, что указывает о полимеризации фосфорсодержащего продукта.

Изучено действие растворов образцов I, II и реактива на сталь Ст3. фосфоинозитида, г/м²·ч. Результаты гравиметрических экспериментов реактива, образцов I и II показаны в таблице 2. Согласно полученным данным, защитный эффект, оказываемый фосфорсодержащими веществами в $3 \%$ растворе $\mathrm{NaCl}$, превышает значение $\mathrm{Z}$ триазолов по отношению к стали Ст3. Наибольшее ингибирующее действие оказывает добавка образца II. В солянокислом растворе величина Z исследуемых образцов I, II и реактива «Sigma» ниже значения защитного эффекта триазолов.

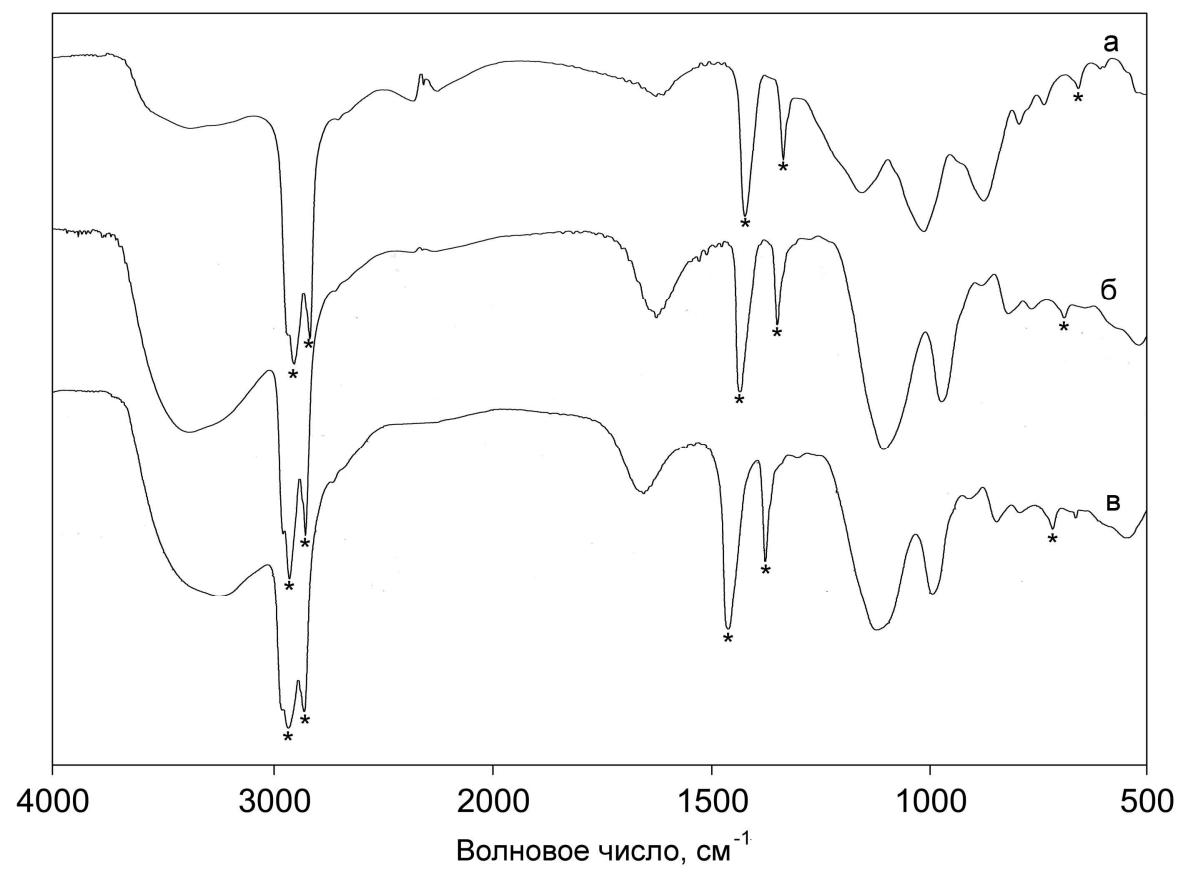

Рис. 1. ИК-спектры поглощения фитинатов: a - реактив; б, в - продукты, полученные из рисовой мучки (б - образец I, в - образец II)

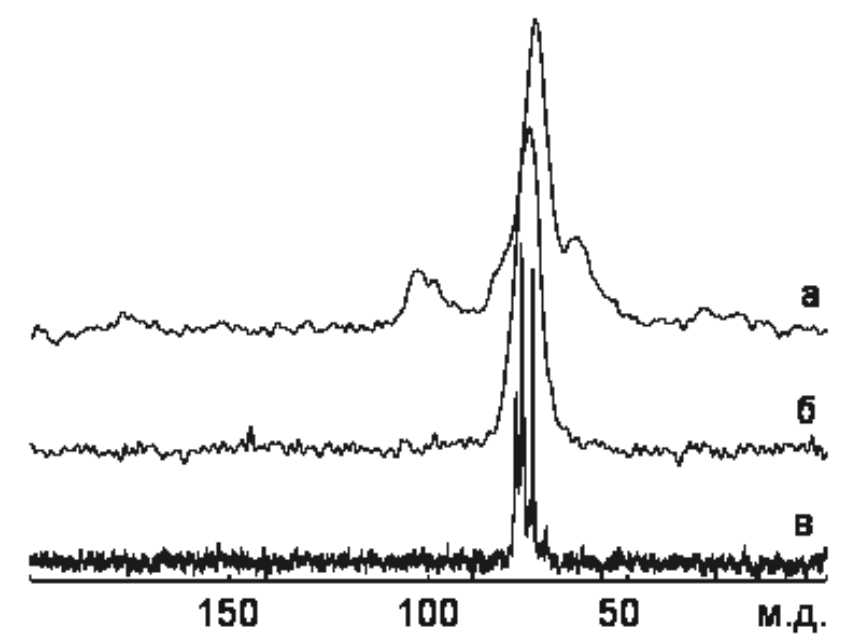

Рис. 2. Спектры ЯМР ${ }^{13} \mathrm{C}$ образцов фитинатов, полученных из рисовой мучки (а) и реактива «Sigma» (б, в - в твердой фазе и растворе, соответственно)

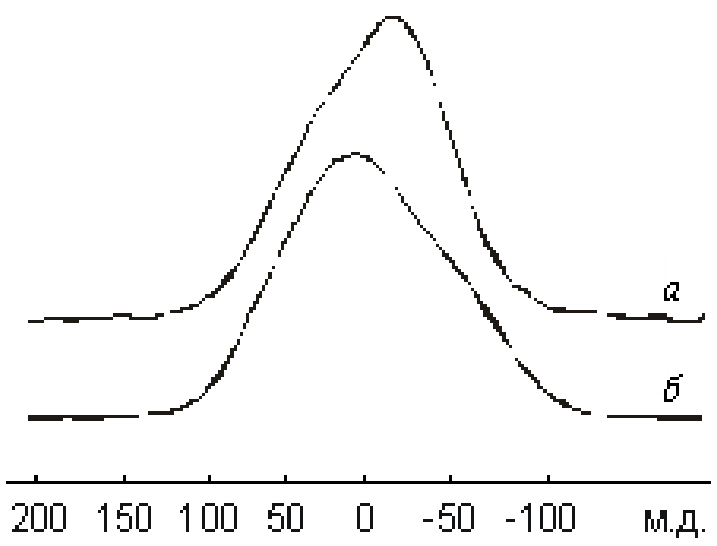

Рис. 3. Статические спектры ЯМР 31Р образца из рисовой мучки (а) и реактива «Sigma» (б) 
Результаты потенциодинамического исследования поверхности стали (табл. 3) также подтверждают данные гравиметрических испытаний. Добавки триазолов и образца I в раствор хлорида натрия приводят к сдвигу анодных и катодных поляризационных кривых в область меньших значений тока и уменьшению значений плотности тока коррозии $\left(\mathrm{I}_{\mathrm{cor}}, \mathrm{M \kappa} \mathrm{A} / \mathrm{cm}^{2}\right)$. Значения коэффициентов торможения анодной $\left(\gamma_{\mathrm{a}}\right)$ и катодной $\left(\gamma_{\mathrm{k}}\right)$ реакций свидетельствуют о преимущественном замедлении анодной реакции коррозионного процесса. В кислой среде наблюдается одинаковое торможение как анодной, так и катодной реакций: значения коэффициентов $\gamma_{\mathrm{a}}$ и $\gamma_{\mathbf{\kappa}}$ мало отличаются друг от друга.

Была изучена морфология поверхности пластин стали. На рисунке 4 представлены микрофотографии поверхности стали Ст3 до и после коррозионных испытаний в растворе $3 \% \mathrm{NaCl}$ и 0,1 н. $\mathrm{HCl}$ с добавкой образца I. Анализ микрофотографий показывает, что во время экспозиции на стальных пластинах образуется пленка, состоящая из агрегатов различных размеров (рис. 4б, в). На поверхности стали, экспонированной в $3 \%$ растворе $\mathrm{NaCl}$ с добавлением фосфорсодержащего продукта, агрегаты имеют глобулярное строение и состоят из более мелких частиц, размер которых составляет 5-20 мкм. По данным энергодисперсионного микроанализа пленки, формирующиеся на поверхности малоуглеродистой стали, содержат фосфор, количество которого изменяется от 1,35\% (экспонирование в $0,1 \mathrm{H.} \mathrm{HCl)} \mathrm{до} \mathrm{1,69 \%} \mathrm{(экспонирова-}$ ние в растворе $\mathrm{NaCl}$ ).

Таблица 2. Среднее значение скорости коррозии стали $\left(K, \Gamma / \mathrm{M}^{2} \cdot\right.$ ч) и защитный эффект $(\mathrm{Z}, \%)$ растворов триазолов и производных инозитгексафосфорной кислоты

\begin{tabular}{|c|c|c|c|c|}
\hline \multirow{3}{*}{ Раствор } & \multicolumn{4}{|c|}{ Сталь Ст3 } \\
\hline & \multicolumn{2}{|c|}{$3 \% \mathrm{NaCl}$} & \multicolumn{2}{|c|}{0,1 н. $\mathrm{HCl}$} \\
\hline & $\mathrm{K}_{\mathrm{cp}}$ & $\mathrm{Z}$ & $\mathrm{K}_{\mathrm{cp}}$ & $\mathrm{Z}$ \\
\hline 1,2,4-триазол & 0,0906 & 55,9 & 0,0383 & 98,3 \\
\hline 3-амино-1,2,4-триазол & 0,1003 & 51,1 & 0,0847 & 96,3 \\
\hline Реактив «Sigma» & 0,042 & 62,5 & 0,417 & 91,0 \\
\hline Образец I & 0,0728 & 64,5 & 1,0537 & 54,5 \\
\hline Образец II & 0,015 & 86,6 & 0,802 & 82,7 \\
\hline
\end{tabular}

Таблица 3. Электрохимические параметры процесса коррозии стали Ст3 в 3\% растворе $\mathrm{NaCl}$ и 0,1 н. растворе $\mathrm{HCl}$ с добавкой фитината аммония и триазолов

\begin{tabular}{|c|c|c|c|c|c|c|}
\hline Раствор & $\mathrm{E}, \mathrm{mB}$ & $\mathrm{b}_{\mathrm{a}}, \mathrm{MB}$ & $\mathrm{b}_{\mathrm{c}}, \mathrm{MB}$ & $\mathrm{I}_{\mathrm{cor}}, \mathrm{MKA} / \mathrm{cm}^{2}$ & $\overline{\gamma_{\mathrm{a}}}$ & $\gamma_{\mathrm{k}}$ \\
\hline \multicolumn{7}{|c|}{$\mathrm{pH}=7,0$} \\
\hline $\mathrm{NaCl}$ & -597 & 118 & 336 & 5,710 & - & - \\
\hline 1,2,4-триазол & -525 & 108 & 561 & 3,787 & 5,0 & 1,3 \\
\hline 3-амино-1,2,4-триазол & -490 & 106 & 861 & 3,587 & 24,4 & 2,0 \\
\hline Образец I & -491 & 43 & 606 & 2,703 & 11,3 & 2,0 \\
\hline \multicolumn{7}{|c|}{$\mathrm{pH}=1,0$} \\
\hline $\mathrm{HCl}$ & -467 & 60 & 105 & 41,93 & & \\
\hline 1,2,4-триазол & -460 & 48 & 140 & 20,3 & 4,9 & 2,7 \\
\hline 3-амино-1,2,4-триазол & -468 & 59 & 172 & 21,9 & 1,3 & 2,4 \\
\hline Образец I & -473 & 74 & 174 & 26,3 & 1,4 & 2,1 \\
\hline
\end{tabular}

*Примечание: $\mathrm{E}$ - потенциал коррозии, $\mathrm{b}_{\mathrm{a}}$ и $\mathrm{b}_{\mathrm{c}}-$ коэффициенты наклона тафелевых участков анодной и катодной кривых соответственно; $\mathrm{I}_{\text {кор }}$ - плотность тока коррозии, $\gamma_{\mathrm{a}}$ - коэффициент торможения анодной реакции; $\gamma_{\mathrm{\kappa}}-$ коэффициент торможения катодной реакции.
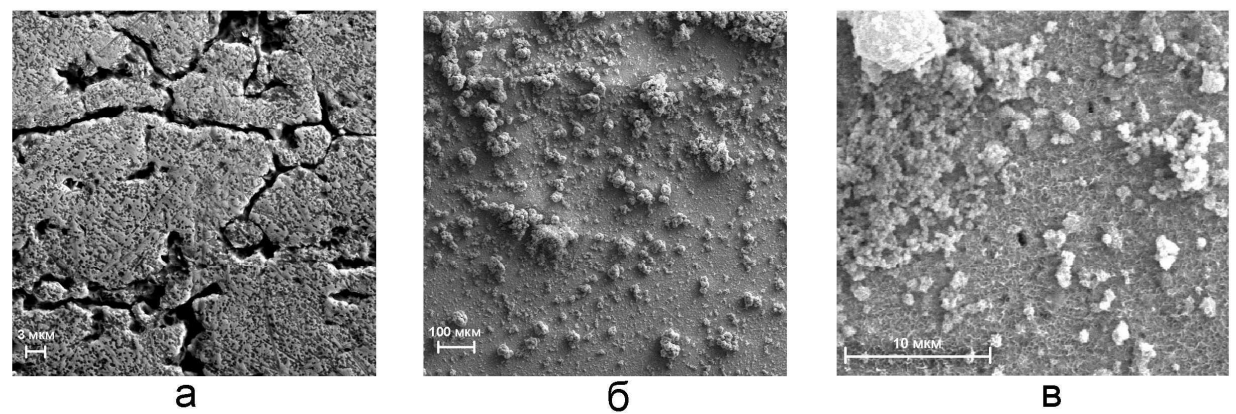

Рис. 4. Микрофотографии исходной поверхности стали Ст3 до (а) и после коррозионных испытаний в $3 \%$ растворе $\mathrm{NaCl}$ (б) и в $0.1 \mathrm{H} . \mathrm{HCl}$ (в) с добавками фосфорсодержащего вещества (образец I) 


\section{Выводы}

1. Установлено, что фосфорсодержащие продукты, выделенные из отходов производства риса (шелухи и мучки), по своему составу близки и относятся к производным пентафосфоинозитида.

2. Добавки фосфорсодержащих веществ, полученных из рисовой мучки, являются ингибиторами коррозии в водно-солевой среде с защитным эффектом 62,5-86,6\%, превышающим действие стандартных ингибиторов коррозии (триазолов).

3. Пленки, формирующиеся на поверхности стальных образцов после коррозионных испытаний в растворе $\mathrm{NaCl}$ и $\mathrm{HCl}$ с добавками солей фитиновой кислоты, содержат фосфор от 1,35 до 1,69\%.

Авторы выражают благодарность кандидату геолого-минералогических наук Н.Н. Баринову за помощь в экспериментальной работе, обработке и обсуждении результатов.

\section{Список литературь}

1. Abdel-Gaber A.M., Abd-El-Nabey B.A., Saadawy M. The role of acid anion on the inhibition of the acidic corrosion of steel by lupine extract // Corrosion science. 2009. Vol. 51, N5. Pp. 1038-1042.

2. Raja P.B., Sethuraman M.G. Inhibition of corrosion of mild steel in sulphuric acid medium by Calotropis procera // Pigment \& Resin Technology. 2009. V. 38, N1. Pp. 33-37.

3. Premkumar P., Kannan K., Natesan M. Thyme extract of Thymus vulgar as volatile corrosion inhibitor for mild steel in $\mathrm{NaCl}$ environment // Asian journal of chemistry. 2008. Vol. 20, N1. Pp. 445-451.

4. Х Харченко У.В., Макаренко Н.В., Сафронов П.П., Карабцов А.А., Ковехова А.В., Земнухова Л.А. Защитное действие отходов переработки растительного сырья на коррозию стали в агрессивных средах // Журнал прикладной химии. 2008. Т. 81, №9. С. 1484-1489.

5. Колзунова Л.Г., Земнухова Л.А., Федорищева Г.А., Куриленко Л.Н., Сергиенко В.И. Использование ультрафильтрации для извлечения солей фитиновой кислоты из отходов производства риса // Журнал прикладной химии. 2000. Т. 73, №10. С. 1644-1651.

6. Raboy Vol. Myo-inositol-1,2,3,4,5,6-hexakisphosphate // Phytochemistry. 2003. Vol. 64, N6. Pp. 1033-1043.

7. Qafsaoui W., Blanc Ch., Roques J., Pebere N., Srhiri A., Mijoule C. Pitting corrosion of copper in sulphate solutions: inhibitive effect of different triazole derivative inhibitors // Journal of Applied Electrochemistry. 2001. Vol. 31, N2. Pp. 223-231.

8. Накамото К. ИК-спектры и спектры КР неорганических и координационных соединений. М., 1991. 536 с.

Поступило в редакцию 30 октября 2012 г.

Makarenko N.V., Kharchenko U.V., Slobodyuk A.B., Zemnukhova L.A. PHOSPHOPROUS-CONTAINING PRODUCTS PREPARED FROM RICE WASTES AND THEIR ANTICORROSIVE PROPERTIES

Institute of Chemistry, Far Eastern Branch of the Russian Academy of Sciences, pr. 100-letiia Vladivostoka, 159,

Vladivostok, 690022 (Russia), e-mail: makarenko@ich.dvo.ru

A phosphoprous-containing products was extracted from rice bran and rice husk to examine their element composition and structure by the IR and NMR spectroscopy, X-ray diffraction (XRD), and differential thermal analysis (DTA). Influence of organophosphorus compounds prepared from the rice production waste on corrosion of low-carbon steel St3 in aggressive media was studied by the gravimetric and potentiodynamic methods, as well as by the scanning electron microscopy

Keywords: rice bran, husk, phytic acid derivatives, corrosion inhibitors.

\section{References}

1. Abdel-Gaber A.M., Abd-El-Nabey B.A., Saadawy M. Corrosion science, 2009, vol. 51, no. 5, pp. $1038-1042$.

2. Raja P.B., Sethuraman M.G. Pigment \& Resin Technology, 2009, vol. 38, no. 1, pp. 33-37.

3. Premkumar P., Kannan K., Natesan M. Asian journal of chemistry, 2008, vol. 20, no. 1, pp. 445-451.

4. Kharchenko U.V., Makarenko N.V., Safronov P.P., Karabtsov A.A., Kovekhova A.V., Zemnukhova L.A. Zhurnal prikladnoi khimii, 2008, vol. 81, no. 9, pp. 1484-1489. (in Russ.).

5. Kolzunova L.G., Zemnukhova L.A., Fedorishcheva G.A., Kurilenko L.N., Sergienko V.I. Zhurnal prikladnoi khimii, 2000, vol. 73, no. 10, pp. 1644-1651. (in Russ.).

6. Raboy Vol. Phytochemistry, 2003, vol. 64, no. 6, pp. 1033-1043.

7. Qafsaoui W., Blanc Ch., Roques J., Pebere N., Srhiri A., Mijoule C. Journal of Applied Electrochemistry, 2001, vol. 31, no. 2, pp. 223-231.

8. Nakamoto K. IK spektry i spektry KR neorganicheskikh i koordinatsionnykh soedinenii. [IR and Raman Spectra of Inorganic and Coordination Compounds]. Moscow, 1991, $536 \mathrm{p.}$

\footnotetext{
* Corresponding author.
} 